\title{
Preparation of bronchoalveolar lavage fluid with microscope slide smears
}

\author{
A.B. Thompson*, H. Teschler**, Y.M. Wang**, \\ N. Konietzko**, U. Costabel**
}

Preparation of bronchoalveolar lavage fluid with microscope slide smears. A.B. Thompson, H. Teschler, Y.M. Wang, N. Konietzko, U. Costabel. C ERS Journals Ltd 1996.

ABSTRACT: The method of preparation of bronchoalveolar lavage fluid (BALF) for cytological examination can significantly affect the results of cellular quantitation. Investigations have shown that cytocentrifugation leads to an underestimation of the number of lymphocytes and membrane filter preparation to an underestimation of the number of neutrophils. As a simple alternative to these two techniques, BALF cells could be prepared by the microscope slide smear technique, which is familiar as the means for preparing peripheral blood for differential counts.

In order to compare cell differentials determined by microscope slide technique with differentials resulting from cytocentrifugation, cells were isolated from 35 BALF samples using standard methods, and counted using a haematocytometer. Forty thousand cells in $200 \mu \mathrm{L}$ were prepared by cytocentrifugation $(3 \mathrm{~min}, 57 \times \mathrm{g}$; Cytospin 2) and $5 \times 10^{5}$ cells in $5 \mu \mathrm{L}$ by microscope slide smear. Both samples were air-dried, stained using May-Grünwald Giemsa stain, and 600 cells were counted to obtain differentials. To test the adequacy of sampling by the microscope slide smear technique, known quantities of lymphocytes or neutrophils were added to fixed numbers of BALF cells, microscope slide smears prepared, and differentials determined on 600 cells. The resulting differentials were compared to the calculated differentials.

Preparation of BALF cells with the microscope slide smear technique yielded well-preserved cell morphology. Compared to cytocentrifugation, microscope slide smear preparations had significantly higher percentages of lymphocytes. The microscope slide smears for the samples with predetermined numbers of cells yielded lymphocyte and neutrophil percentages which did not differ from the calculated differentials (59.6 $\pm 1.5 v s 59.6 \pm 5.2 \%$ and $54.6 \pm 6.0 v s 53.1 \pm 6.0 \%$, respectively). Varying the number of cells counted from 100 to 800 confirmed the reproducibility of the counts for counting 600 cells. Using $5 \times 10^{5}, 2.5 \times 10^{5}$, or $1 \times 10^{5}$ cells per preparation demonstrated that adequate specimens could be obtained from as few as $1 \times 10^{5}$ cells.

Thus, microscope slide smear preparation is a simple and accurate method for the quantitation of bronchoalveolar lavage fluid cytology.

Eur Respir J., 1996, 9, 603-608.
*Section of Pulmonary and Critical Care Medicine, Dept of Internal Medicine, University of Nebraska Medical Center, Omaha, NE, USA. **Dept of Pneumonology, Medical Faculty, University of Essen, Essen, Germany,

Correspondence: A.B. Thompson Section of Pulmonary and Critical Care Medicine

Dept of Internal Medicine

University of Nebraska Medical Center $600 \mathrm{~S} 42 \mathrm{nd} \mathrm{St}$

Omaha

NE 68198-5300

USA

Keywords: Bronchoalveolar lavage cytocentrifugation cytology

microscope slide smear

Received: November 151994

Accepted after revision November 71995
Bronchoalveolar lavage (BAL) is a useful tool in the sampling of the lower respiratory tract both for clinical indications and for research-related investigations [1$3]$. One important parameter for the analysis of BAL is the quantitation of the number and types of cells recovered. A number of different methods have been developed for preparation of BAL fluid (BALF) cells for cytological examination, including cytocentrifugation, membrane filtration, and centrifugation onto a cover slip [1, 3-6].

Careful investigations have demonstrated that the method of processing of BALF can significantly affect data interpretation [7-12]. For example, the two most widely utilized methods, cytocentrifugation and membrane filtration, underestimate the content of lymphocytes and neutrophils, respectively $[7,9,10]$. Thus, methodologies must be carefully validated.

Processing cells in suspension for cytological investigation is easily and quickly accomplished by streaking a cell suspension onto a microscope slide with the aid of a straight edge, typically a second microscope slide. This method has been classically employed and validated in clinical haematology laboratories for peripheral blood smears. Similarly, smears of BALF cells can be prepared by streaking cells onto a glass microscope slide [13-15]. The purpose of this investigation was to determine whether microscope slide smears can be used to accurately quantitate the contents of BALF. 


\section{Methods}

\section{Experimental design}

In order to compare the microscope slide technique to a widely used method, clinical BALF samples were processed both by cytocentrifugation and by the microscope slide smear technique and cell differentials were determined. To further characterize the accuracy of the recovery of inflammatory cells by the slide smear technique, known numbers of lymphocytes or neutrophils were added to BALF cells and the calculated differential of the added cells was compared to the actual, counted differential of the added cells. Finally, in order to characterize the sampling efficiency of the microscope slide smear technique, the number of cells used to make the smear and the number of cells counted for each smear were investigated. The investigation conformed to the regulations of the Institutional Ethics Committee.

\section{Bronchoalveolar lavage and bronchoalveolar lavage fluid processing}

Fibreoptic bronchoscopy and BAL were performed for clinical indications using the methods previously described [13-15]. Anaesthesia of the upper airways was achieved by atomization of $4 \mathrm{~mL}$ of $2 \%$ lidocaine. The airways below the vocal cords were further anaesthetized by the instillation of up to $10 \mathrm{~mL}$ of $1 \%$ lidocaine, as needed to suppress cough. BAL was performed by instilling and immediately retrieving five $20 \mathrm{~mL}$ aliquots of normal saline. Lavage was performed at one site, either the right middle lobe or lingula. All lavage fluid aliquots were pooled prior to analysis. The mean fluid return for the clinical samples was $53 \pm 3 \%$.

Cell counts were determined on unprocessed fluid using a haematocytometer. Mucus was removed from the fluid using a single layer of cotton gauze. The cells were washed once by centrifugation $(10 \mathrm{~min}, 300 \times \mathrm{g})$ and resuspended in minimal essential medium (Biochrom $\mathrm{KG}$, Berlin) supplemented with $0.2 \%$ bovine serum albumin (Behring Werke AG, Marburg) and $0.1 \%$ ethylenediamine tetra-acetic acid (EDTA) at $\mathrm{pH} 7.4$ (MBE). BALF cells were prepared by cytocentrifugation using standard methods, air-dried, and stained with MayGrünwald Giemsa stain [2].

After removal of the fraction of cells for cytocentrifugation, the cells were centrifuged ( $3 \mathrm{~min}, 300 \times \mathrm{g}$ ) and brought to a concentration of $1 \times 10^{8}$ cells $\cdot \mathrm{mL}^{-1}$ by adding MBE. Five microlitres of the resulting cell suspension $\left(5 \times 10^{5}\right.$ cells $)$ were placed on a microscope slide, entrained, and spread over the slide with an even stroke of a second microscope slide. The final number of cells used to make the smear was adjusted, if necessary, according to the viscosity of the cell suspension. The cells were air-dried and stained with May-Grünwald Giemsa stain.

Macrophages, lymphocytes, neutrophils, eosinophils and basophils were counted to determine cell differentials. A total of 600 cells was counted both for the microscope slide smear and for the cytocentrifugation preparations. Care was taken in the quantitation of the microscope slide smears to sample areas of the slide with an even distribution of cells. For cases with an uneven distribution, three areas of the slide representing the point of origin of the smear, the centre of the smear, and the leading edge of the smear were counted.

Determination of the accuracy of the recovery of BALF cells by the microscope slide smear technique

In order to define the accuracy of the recovery of BALF cells by the microscope slide smear technique, BALF from 35 clinical samples was investigated. The patients underwent BAL for a variety of clinical indications, including idiopathic pulmonary fibrosis $(n=7)$, bronchogenic carcinoma $(n=6)$, pneumonia $(n=6)$, bronchiolitis obliterans organizing pneumonia $(n=5)$, pneumoconiosis $(n=5)$, haematological malignancies $(n=3)$, and sarcoidosis $(n=3)$. The BALF samples were prepared both by microscope slide smear and cytocentrifugation. The differentials were compared for each of the cell types enumerated.

The accuracy of the recovery of lymphocytes and neutrophils by the microscope slide smear technique was determined by adding known numbers of either lymphocytes or neutrophils to known numbers of BALF cells and comparing the expected, calculated differential to the actual, counted differential.

Lymphocytes were prepared from peripheral blood by density gradient centrifugation over Ficoll (Biochrom $\mathrm{KG}$, Berlin), washed once and brought to a concentration of $1 \times 10^{6}$ cells $\cdot \mathrm{mL}^{-1}$. Similarly, neutrophils were prepared from peripheral blood by dextran sedimentation (4.5 gm\%, mixed with an equal volume of peripheral blood), washed once, and brought to a concentration of $1 \times 10^{6}$ cells $\cdot \mathrm{mL}^{-1}$. BALF cells were processed in the usual manner and brought to a concentration of $1 \times 10^{6}$ cells $\cdot \mathrm{mL}^{-1}$.

Aliquots of either the peripheral blood neutrophil or lymphocyte preparations and portions of BALF cells containing less than 5\% neutrophils or 14-18\% lymphocytes, respectively, were mixed. The proportions of the mixed cell suspensions were adjusted to yield $1 \mathrm{~mL}$ of cell suspension containing calculated ratios of the peripheral blood cells ranging 5-95\%. Just before mixing, cell differentials and cell counts were repeated on the cell suspensions to assure accuracy of the calculated differentials. Two hundred microlitres of the cell mixtures were taken for cytocentrifugation. The cell mixtures were then centrifuged and the cells resuspended in 100 $\mu \mathrm{L}$ of phosphate-buffered saline (PBS) for the preparation of microscope slide smears.

The cell preparations were air-dried and cell differentials were determined by counting a total of 600 macrophages, lymphocytes, neutrophils, eosinophils and basophils, as described above.

\section{Determination of the efficiency of cell recovery by the microscope slide smear technique}

In order to determine the effect of the number of cells used in the preparation of the smears and the number of 
cells counted, cells from eight clinical BALF samples were investigated. The number of cells used in the preparation of smears was adjusted to $5 \times 10^{5}$ (the standard number), $2.5 \times 10^{5}$, and $1 \times 10^{5}$, and 600 cells were counted for each preparation. The resulting differentials were compared for macrophages, lymphocytes and neutrophils. Additionally, cell differentials were determined on smears prepared with $5 \times 10^{5}$ cells by sequentially counting and recording the results for 100, 200, 400, 600 and 800 cells on five different occasions. The variability of the counts, as measured by the coefficient of variation $(\mathrm{CoV}=(\mathrm{sD} / \mathrm{mean}) \times 100)$ were compared.

\section{Statistics}

Data are expressed as mean \pm SD. Comparison of paired data were made with the paired Student's t-test. The results of the comparisons for specific cell types in the clinical samples and from the mixing experiments were plotted as scattergrams and visually compared to the line of identity. A Pearson correlation coefficient was calculated for each cell type enumerated. To analyse the agreement between the calculated results and the actual results obtained from the mixing experiments, the differences in the percentage of lymphocytes and neutrophils were compared against the average of the two results. The potential bias of the results and the limits of agreement were expressed as the mean difference $\pm \mathrm{SD}$ and the $95 \%$ confidence limits (95\% CL) as described by Bland and Altman [16]. The results for the investigation of the effects of varying cell numbers in the smear preparations were compared using analysis of variance (ANOVA). The results for the investigation of varying the number of cells counted were expressed as the CoV and compared using ANOVA. Statistical calculations were performed on a PC using the CSS statistical program.

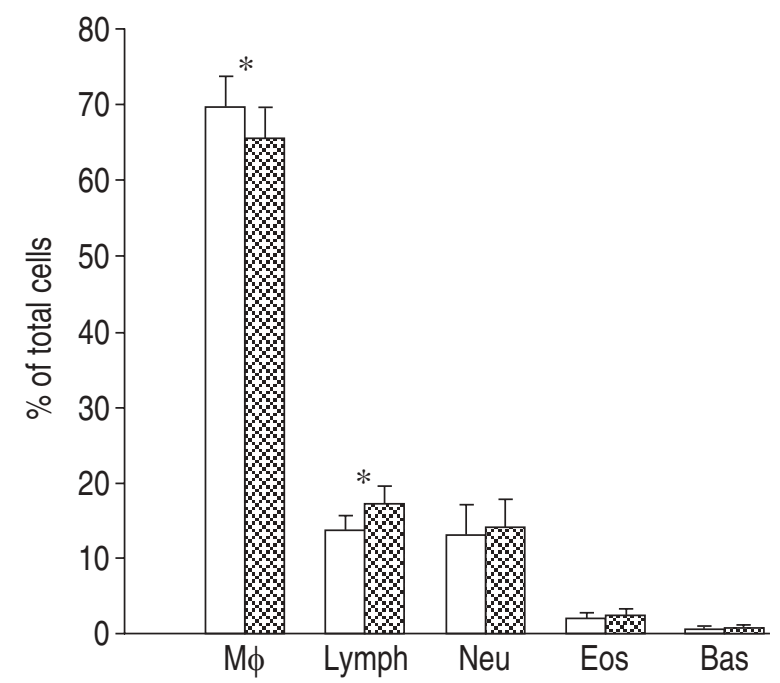

Fig. 1. - Cell recovery. Microscope slide smear technique vs cytocentrifugation. Cell differentials determined for 600 cells from 35 clinical samples and compared for the two preparative techniques. $\mathrm{M} \phi$ : macrophages; Lymph: lymphocytes; Neu: neutrophils; Eos: eosinophils. $\square$ : cytocentrifugation; $\square$ : microscope slide smear technique. *: $\mathrm{p}<0.05$.

\section{Results}

Examination of cells prepared by the microscope slide technique demonstrated that the morphology of granulocytes and lymphocytes was well preserved and that BALF cell types were easily distinguished. Comparison of the results of the 35 clinical samples prepared by microscope slide smears and cytocentrifugation showed that the percentage of macrophages enumerated in the microscope slide smears was lower and the percentage of lymphocytes was higher than the percentages found by cytocentrifugation (fig. 1). Comparison of the individual data for the quantitation of lymphocytes demostrated an apparent systematic underestimation of lymphocytes by cytocentrifugation (fig. 2). A similar comparison of the data for neutrophil quantitation did not show any

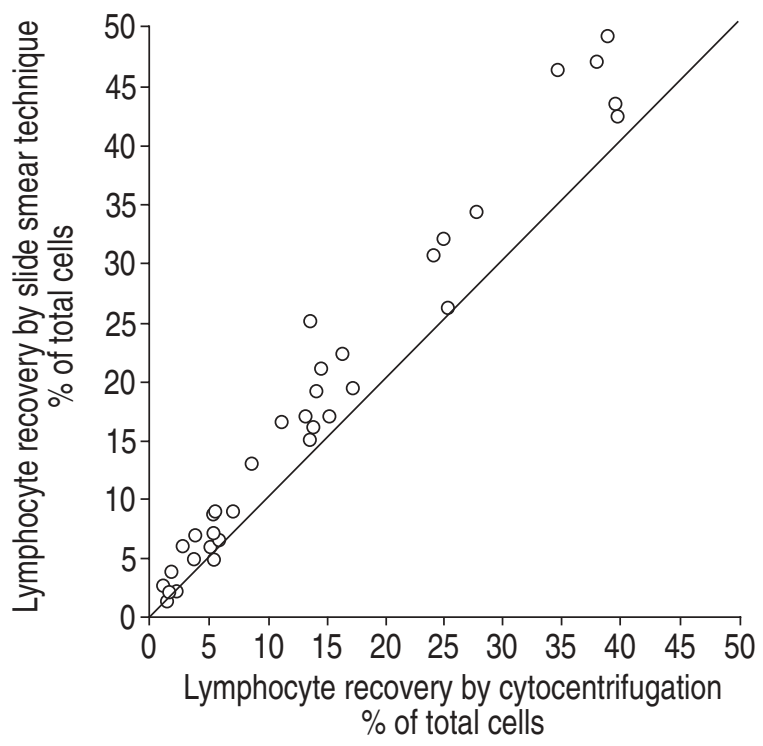

Fig. 2. - Lymphocyte recovery. Scattergram for the lymphocyte recovery from the 35 clinical samples as determined by the two preparative techniques. The solid line is the line of identity.

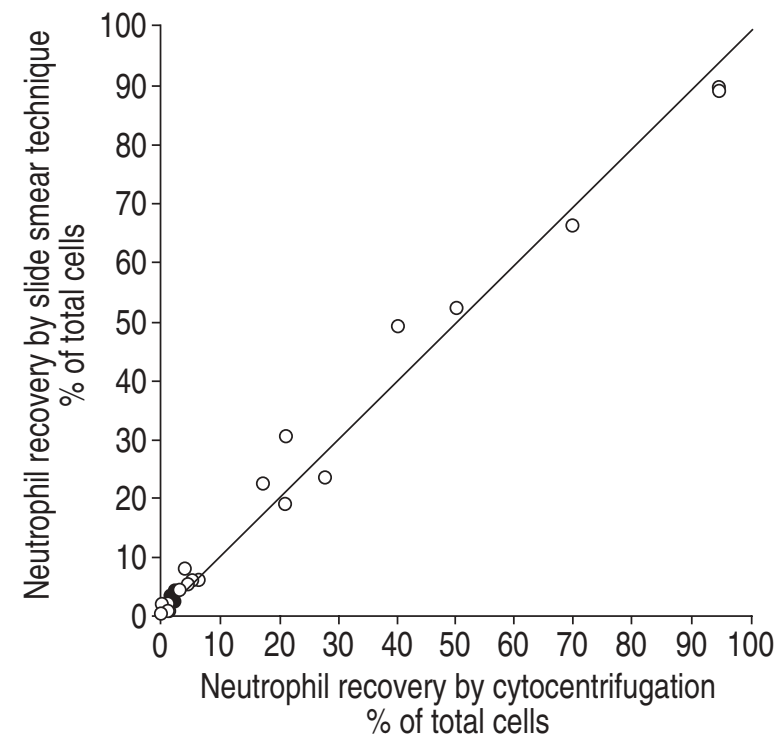

Fig. 3. - Neutrophil recovery. Scattergram for the neutrophil recovery from the 35 clinical samples as determined by the two preparative techniques. The solid line is the line of identity. 
Table 1. - Comparison of differential cell counts as determined by microscope slide smear technique and centrifugation

\begin{tabular}{|c|c|c|c|c|}
\hline \multirow[t]{2}{*}{ Sample } & \multicolumn{2}{|c|}{ Counted differentials \% } & \multirow{2}{*}{$\begin{array}{c}\text { Calculated } \\
\text { differentials } \\
\%\end{array}$} & \multirow[t]{2}{*}{ p-value } \\
\hline & $\begin{array}{l}\text { Slide smear } \\
\text { technique }\end{array}$ & Cytocentrifugation & & \\
\hline \multicolumn{5}{|c|}{ Clinical samples $(n=35)$} \\
\hline Macrophages & $65.7 \pm 24.2$ & $69.8 \pm 24.6$ & NA & $<0.001$ \\
\hline Lymphocytes & $17.2 \pm 14.3$ & $13.7 \pm 12.3$ & NA & $<0.001$ \\
\hline Neutrophils & $14.0 \pm 24.2$ & $13.2 \pm 24.9$ & NA & 0.09 \\
\hline Eosinophils & $2.5 \pm 5.4$ & $2.2 \pm 4.8$ & NA & 0.18 \\
\hline Basophils & $0.89 \pm 1.4$ & $0.85 \pm 1.5$ & NA & 0.65 \\
\hline \multicolumn{5}{|l|}{ Mixing experiments ${ }^{\dagger}$} \\
\hline \multirow[t]{2}{*}{ Lymphocytes $(n=21)$} & $59.6 \pm 23.0$ & NA & $59.6 \pm 23.4$ & 0.94 \\
\hline & NA & $53.8 \pm 23.1$ & $59.6 \pm 23.4$ & 0.004 \\
\hline Neutrophils $(\mathrm{n}=25)$ & $54.6 \pm 29.2$ & NA & $53.1 \pm 28.9$ & 0.14 \\
\hline
\end{tabular}

NA: not applicable. $\uparrow$ : mixing known numbers of lymphocytes and bronchoalveolar lavage fluid cells.

Table 2. - Correlations between differential cell counts as determined by microscope slide smear technique and cytocentrifugation

\begin{tabular}{|c|c|c|c|}
\hline \multirow[t]{2}{*}{ Sample } & \multicolumn{3}{|c|}{ Correlations $\left(\mathrm{r}^{2}\right)$} \\
\hline & $\begin{array}{l}\text { Slide smear } \\
\text { vs Cyto }\end{array}$ & $\begin{array}{l}\text { Slide smear } \\
v s \text { calculated }\end{array}$ & $\begin{array}{l}\text { Cyto vs } \\
\text { calculated }\end{array}$ \\
\hline \multicolumn{4}{|c|}{ Clinical samples $(\mathbf{n}=35)$} \\
\hline Macrophages & 0.96 & NA & NA \\
\hline Lymphocytes & 0.97 & NA & NA \\
\hline Neutrophils & 0.99 & NA & NA \\
\hline Eosinophils & 0.97 & NA & NA \\
\hline Basophils & 0.83 & NA & NA \\
\hline \multicolumn{4}{|l|}{ Mixing experiments } \\
\hline Lymphocytes $(\mathrm{n}=21)$ & NA & 0.97 & 0.89 \\
\hline Neutrophils $(n=25)$ & NA & 0.97 & NA \\
\hline
\end{tabular}

Cyto: cytocentrifugation. NA: not applicable.

difference for the two methods (fig. 3). The mean value for the lymphocytes prepared by microscope slide smear technique $(17.2 \pm 14.3 \%)$ was higher by $3.5 \%$ than in the cytocentrifuge preparations $(13.7 \pm 12.3 \%)$ (table 1$)$. This difference was reflected in the mean percentage of macrophages, which was $4.1 \%$ lower in the microscope slide smears than in the cytocentrifuge preparations. No differences in the mean values were noted for neutrophils, eosinophils, or basophils (table 1). There were high correlations for the results between the two methods (table 2).

Since cytocentrifugation has previously been noted to underestimate the number of lymphocytes, it was hypothesized that the differences in the percentages of macrophages and lymphocytes reflected accurate quantitation by microscope slide smear and underestimation of lymphocytes by cytocentrifugation. This possibility was tested by mixing known numbers of lymphocytes and BALF cells. The results of these experiments confirmed that the microscope slide smear technique accurately quantitates the percentage of lymphocytes and that cytocentrifugation underestimates lymphocytes (table 1). Plotting the differences between the calculated percentage of lymphocytes and the actual results both for the microscope slide smears and cytocentrifugation confirmed
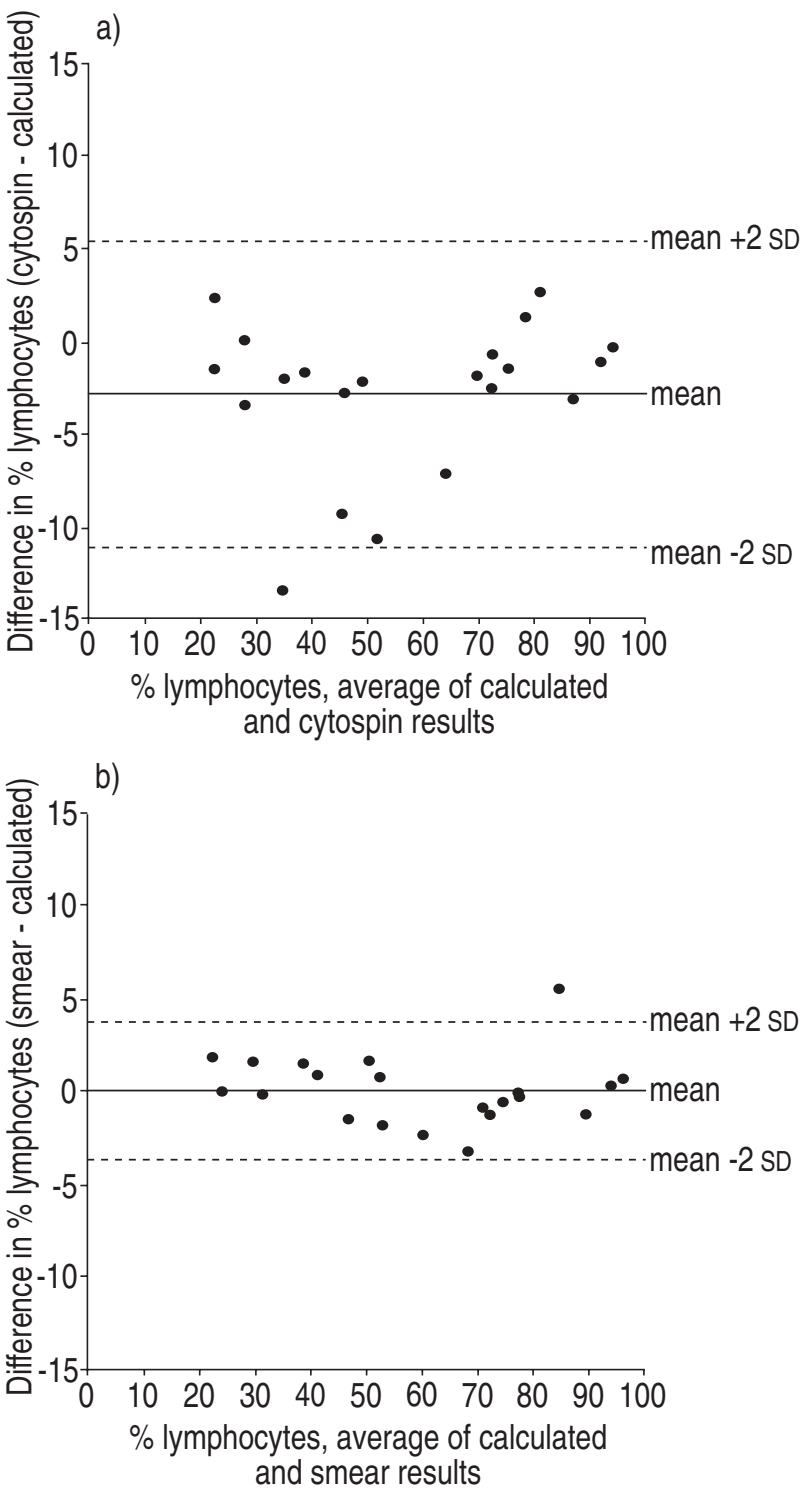

Fig. 4. - Mixing experiments, lymphocyte recovery. The results for lymphocyte recovery for: a) cytocentrifugation (cytospin), b) the microscope slide smear technique (smear); plotted as the difference in lymphocyte percentage determined by the two techniques compared to the calculated percentage $v s$ the mean of the results. 


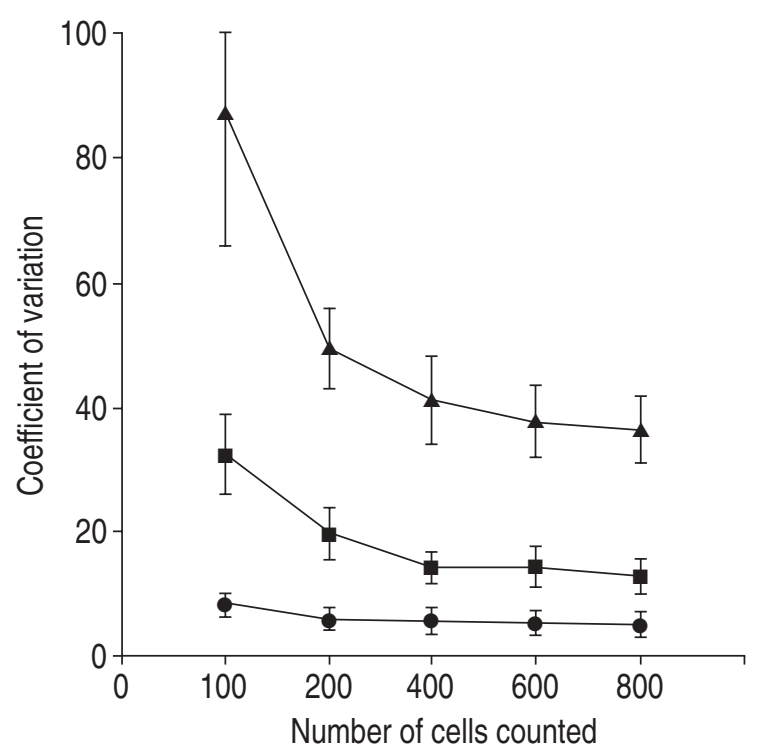

Fig. 5. - The effect of varying the number of cells counted upon the variability of the differential cell counts for macrophages, lymphocytes and neutrophils. ——: macrophages; —-: lymphocytes; - - —: neutrophils.

the bias of cytocentrifugation to lose lymphocytes (mean difference $=-2.88 \pm 4.11 \%, 95 \%$ CL -1.33 to $-4.43 \%$ ) (fig. 4a), and demonstrated no bias for the microscope slide smear technique (mean difference $0.03 \pm 1.87 \%, 95 \% \mathrm{CL}$ 0.74 to $-0.68 \%$ ) (fig. 4 b). A similar analysis of the recovery of neutrophils by microscope slide technique confirmed the accuracy of the quantitation of neutrophils (table 1).

Adjusting the number of cells used in the microscope slide smears did not effect the results, down to $1 \times 10^{5}$. The cell differentials did not differ for preparations containing different numbers of cells. For preparations of $5 \times 10^{5}, 2.5 \times 10^{5}$ and $1 \times 10^{5}$ cells the results were, respectively, $73.4 \pm 25.6,72.9 \pm 23.7$ and $72.8 \pm 23.5 \%(p=0.99)$ for macrophages, $23.2 \pm 26.5,22.7 \pm 25.3$ and $22.8 \pm 25.2 \%$ $(\mathrm{p}=0.99)$ for lymphocytes, and $3.3 \pm 3.9,3.74 \pm 4.3$ and $3.6 \pm 4.7 \%(p=0.97)$ for neutrophils. The CoV of the cell differentials tended to lessen as more cells were counted (fig. 5). For alveolar macrophages, there were no statistically significant differences between any of the counts. However, lymphocytes and neutrophils were present in markedly lower percentages than were macrophages ( 3 out of 8 samples contained $<10 \%$ lymphocytes and 7 out of 8 samples contained $<10 \%$ neutrophils). Differential counts of these cells were, thus, more prone to large differences in the $\mathrm{CoV}$ resulting from small absolute differences in cell counts. As a result of this, there were statistically significant differences in the CoV both for lymphocytes $(\mathrm{p}=0.01)$ and neutrophils $(\mathrm{p}=0.01)$. The CoV fell until 400-600 cells were counted (fig. 5).

\section{Discussion}

The microscope slide smear technique was found to accurately quantitate inflammatory cells in BALF, without underestimation of either neutrophils or lymphocytes. It was demonstrated that counting 600 cells is a practical limit to assure minimal variability in the determination of cell differentials, and that valid smears can be made with as few as $1 \times 10^{5}$ cells. The reliable production of high quality microscope slide smears does require some training of the technical support personnel. However, the method is a straightforward modification of the time-honoured technique used to produce smears of peripheral blood. There is extensive experience with the use of this technique for the preparation of peripheral blood smears and it is easily learned.

The number of cells used in the preparation of microscope slide smears is higher than that used for other preparative methods. For example, the number of cells used for cytocentrifugation ranges from $5 \times 10^{4}$ to $1 \times 10^{5}$, and the number used for membrane filtration is $1 \times 10^{5}$ $[3,6]$. The use of $1 \times 10^{5}$ cells for microscope slide smears leads to preparations with widely spaced cells, which are laborious to count. The need for higher numbers of cells may limit the use of microscope slide smears in situations where the yield of cells may be low, e.g. the "bronchial" sample resulting from small lavage volumes [17], or when large numbers of BALF cells are needed for other purposes, e.g. in vitro culture of macrophages.

The data confirm previous results, which demonstrated that preparation of cells by cytocentrifugation yields results which correlate well with other preparative methods, but leads to a systematic underestimation of lymphocytes $[7,9,10]$. Other studies have not found that cytocentrifugation is responsible for loss of lymphocytes. In one study, it was found that differences in lymphocyte counts were due to the addition of serum to BALF [11]. In a second study, differences in lymphocyte counts were felt to be due to differences in methods used to fix and stain the cells [12]. Neither of these factors could have contributed to the differences in lymphocyte enumeration found in this study. Serum was not used in the preparation of the BALF cells and all of the preparations were identically fixed and stained. Possible errors introduced by fixation and staining were not addressed by the experimental design of the study.

The bias demonstrated for loss of lymphocytes by cytocentrifugation was low $(-2.88 \pm 4.11 \%, 95 \% \mathrm{CL}-1.33$ to $-4.33 \%$ ), suggesting that findings derived from cytocentrifugation and microscope slide smears would differ only slightly. However, the largest losses occurred in samples with lymphocyte percentages around 50\%, a result expected if the loss is proportional to the number of lymphocytes present and if the results are expressed as percentage of total cells. Unfortunately, the clinical significance of an elevation in lymphocytes is most crucial at percentages approaching the range of values for which the losses were greatest. Thus, it is important to account for differences in preparative techniques when comparing results from different laboratories or when establishing normal values for an institution.

In conclusion, the microscope slide technique for the preparation of bronchoalveolar lavage fluid cells for cytological examination accurately quantitates inflammatory cells. The microscope slide smear technique requires more cells per preparation than do other methods, but 
the quickness and ease of performance and the quality of the resulting preparations suggest that the method is suitable for widespread application.

\section{References}

1. Reynolds HY. Bronchoalveolar lavage. Am Rev Respir Dis 1987; 135: 250-263.

2. Klech H, Hutter C. Clinical guidelines and indications for bronchoalveolar lavage (BAL): Report of the European Society of Pneumology Task Group on BAL. Eur Respir J 1990; 3: 937-974.

3. Linder J, Rennard SI. In: Bronchoalveolar Lavage. 1st edn. Chicago, ASCP Press, 1988.

4. Laviolette M, Carreau M, Coulombe R. Bronchoalveolar lavage cell differential on microscope glass cover: a simple and accurate technique. Am Rev Respir Dis 1988; 138: 451-457.

5. Crystal RG, Reynolds HY, Kalica AR. Bronchoalveolar lavage: the report of an international conference. Chest 1986; 90: 122-131.

6. European Society of Pulmonology Task Group on BAL. Technical recommendations and guidelines for bronchoalveolar lavage (BAL). Eur Respir J 1989; 2: 561-585.

7. Saltini C, Hance AJ, Ferrans VJ, Basset F, Bitterman PB, Crystal RG. Accurate quantification of cells recovered by bronchoalveolar lavage. Am Rev Respir Dis 1984; 130: 650-658.

8. Baughman R, Strohofer S, Kim CK. Variation of differential cell counts of bronchoalveolar lavage fluid. Arch Pathol Lab Med 1986; 110: 341-343.

9. Fleury-Feith J, Escudier E, Pocholle MJ, Carre C, Bernaudin $\mathrm{JF}$. The effects of cytocentrifugation on differential cell counts in samples obtained by bronchoalveolar lavage. Acta Cytol 1987; 31: 606-610.

10. Thompson AB, Robbins RA, Ghafouri MA, Linder J, Rennard SI. Bronchoalveolar lavage fluid processing: effect of membrane filtration preparation on neutrophil recovery. Acta Cytol 1989; 33: 544-549.

11. Wilcox M, Kervitsky A, Watters LC, King TEJ. Quantification of cells recovered by bronchoalveolar lavage: comparison of cytocentrifuge preparations with the filter method. Am Rev Respir Dis 1988; 138: 74-80.

12. Mounami H, Garaud P, Diot P, LeMarie E, Anthonioz P. Quantification of cell loss during bronchoalveolar lavage fluid processing: effects of fixation and staining methods. Am J Respir Crit Care Med 1994; 149: 636-640.

13. Costabel U, Teschler H, Guzman J. Bronchiolitis obliterans organizing pneumonia (BOOP): the cytological and immunocytological profile of bronchoalveolar lavage. Eur Respir J 1992; 5: 791-797.

14. Costabel U, Bross KJ, Matthys H. The immunoperoxidase slide assay: a new method for the demonstration of surface antigens on bronchoalveolar lavage cells. Bull Eur Physiopathol Respir 1985; 21: 381-387.

15. Costabel U, Bross KJ, Ruhle KH, Lohr GW, Matthys H. Ia-like antigens on T-cells and the subpopulations in pulmonary sarcoidosis and in hypersensitivity pneumonitis: analysis of bronchoalveolar and blood lymphocytes. Am Rev Respir Dis 1985; 131: 337-342.

16. Bland JM, Altman DG. Statistical methods for assessing agreement between two methods of clinical measurement. Lancet 1986; i: 307-310.

17. Rennard SI, Ghafouri M, Thompson AB, et al. Fractional processing of sequential bronchoalveolar lavage to separate bronchial and alveolar samples. Am Rev Respir Dis 1990; 141: 208-217. 